\title{
Spatio-Temporal Distribution of Shallow Very-Low- Frequency Earthquakes between December 2020 and January 2021 in Kumano-Nada, Nankai Subduction Zone, Detected by A Permanent Seafloor Seismic Network
}

\section{Yojiro Yamamoto ( $\nabla$ yamamotoy@jamstec.go.jp )}

Japan Agency for Marine-Earth Science and Technology https://orcid.org/0000-0002-0224-8603

\section{Keisuke Ariyoshi}

Japan Agency for Marine-Earth Science and Technology

Shuichiro Yada

Japan Agency for Marine-Earth Science and Technology

Masaru Nakano

Japan Agency for Marine-Earth Science and Technology

\section{Takane Hori}

Japan Agency for Marine-Earth Science and Technology

\section{Express Letter}

Keywords: Nankai Trough, shallow very-low-frequency earthquake, centroid moment tensor (CMT) solution, slow earthquake, Dense Oceanfloor Network System for Earthquakes and Tsunamis (DONET)

Posted Date: November 11th, 2021

DOI: https://doi.org/10.21203/rs.3.rs-1048924/v1

License: (c) (i) This work is licensed under a Creative Commons Attribution 4.0 International License. Read Full License

Version of Record: A version of this preprint was published at Earth, Planets and Space on January 12th, 2022. See the published version at https://doi.org/10.1186/s40623-022-01573-x. 


\section{Abstract}

We estimate the hypocenter locations and the centroid moment tensor solutions of the shallow very-lowfrequency earthquake (sVLFE) activity that occurred in the Kumano-nada region of the Nankai Trough megathrust zone in central Japan from December 2020 to January 2021. Using seafloor observation data, we examined the detailed spatio-temporal distribution of the sVLFE activity. During this episode, the activity area was within the vicinity in which the sVLFE activity has been observed in the past and can be divided into two major parts. The sVLFE activity started from the eastern side and remained there for the first 5 days and then migrated to the western side via secondary expansion. The eastern active area is located just below the outer ridge and coincides with the location where the paleo-Zenith Ridge is subducted. The western activity area is centered between the outer wedge and the outer ridge with the primary active area being at the outer wedge. Comparing the activity in the eastern and western areas, the eastern side is more active, but the individual moment releases on this side are smaller than those on the western side. This may indicate a difference in the fluid pressure along the plate boundary between the eastern and western areas. After the second expansion of the active area, we observed several migration patterns within the expanded area with a faster velocity than those of the initial and second expansions. The direction of these migrations is opposite to that of the first and second expansions. This indicates that the fluid pressure and/or stress level in the sVLFE generation region changed with time within this episode. Furthermore, many waveforms with sVLFE characteristics were observed at only one or a few observation points near the trough axis in the middle to latter half of January 2021. This indicates the occurrence of small-scale sVLFEs in the vicinity of the trough axis at the end of this sVLFE episode.

\section{Introduction}

The Nankai Trough located in central Japan is a well-known megathrust zone where $\mathrm{M} \sim 8$ class earthquakes have repeatedly occurred with intervals of 100-200 years, including the 1944 Tonankai earthquake ( $M w=7.9)$ (e.g., Ando 1975) (Figure 1a). The Philippine Sea Plate is subducting beneath the Amur Plate with an average relative velocity of $6 \mathrm{~cm} \mathrm{yr}^{-1}$ (Argus et al. 2011). Geodetic observation data show that several zones of strong coupling between the overriding and subducting plates exist in the Nankai forearc (Nishimura et al. 2018; Yokota et al. 2016). Adjusted areas of these strong coupling zone are well correlated with the source area of slow earthquakes, whose activities indicate that the intraplate coupling changes with time (Obara and Kato 2016; Behr and Burgmann 2021). Therefore, the intensive monitoring of slow earthquakes is important to understand the nature of the seismogenic zone, which may also help mitigate future disasters.

Most slow earthquakes occur in the transition zone of the intraplate coupling where the seismogenic strong coupling takes on a rheological creeping nature. In the Nankai Trough, slow earthquakes are detected on both the up-dip and down-dip sides of the subduction zones (e.g., Obara and Kato 2016). The activities on the down-dip side have been well studied using dense seismic and geodetic observation networks in the Japanese Islands. For example, Shelly et al. (2006) found that low-frequency earthquakes occurred along the plate boundary, whereas ordinary earthquakes occurred within the subducted oceanic 
crust. Recent studies on the detailed spatio-temporal distribution of deep tectonic tremors demonstrate that slow-slip transients contain a multitude of smaller, temporally clustered fault slips whose migration is controlled by a diffusional process (Kato and Nakagawa 2020). Conversely, land observations provide a limited ability to study slow earthquakes on the up-dip side. Even though Takemura et al. (2019a, b) determined a centroid moment tensor (CMT) for shallow very-low-frequency earthquakes (sVLFEs), they assumed that all sVLFEs occurred along the plate boundary fault. As these events occur outside the network, their estimated locations have large errors in the depth and along-dip directions. The detection capability is also limited due to the distant locations involved. It is necessary to investigate in detail the sVLFE locations without assuming a focal depth and to discuss the relationship between their depths and the plate boundary.

Offshore observations are crucial for detailed studies of slow earthquakes on the up-dip side. Observations using self-pop-up-type ocean bottom seismometers (OBSs) detected low-frequency tremors and earthquakes in Kumano-nada (Obana and Kodaira 2006; Tamaribuchi et al. 2019) and Hyuga-nada (Yamashita et al. 2015). Using broadband OBSs, Sugioka et al. (2012) detected sVLFEs that occurred along the plate boundary fault. The Dense Oceanfloor Network System for Earthquakes and Tsunamis (DONET; gray diamonds in Figure 1; Kaneda et al. 2015; Kawaguchi et al. 2015) was established after 2012 and provides real-time broadband seismometer observation data with a much better quality than pop-up-type OBSs as the seismometers are buried beneath the seafloor (Araki et al. 2013). Using these data, several sVLFE episodes were investigated (Nakano et al. 2016, 2018; Toh et al. 2020); these data provide much more precise source locations of sVLFEs compared with land-based observations. Furthermore, geodetic observations based on pore pressure changes observed at several hundreds of meters below the sea floor in a bore hole revealed the repetition of large-to-small-scale short-term slowslip events beneath the Kumano-nada area (Araki et al. 2017; Ariyoshi et al. 2021).

A short-term slow-slip event (SSE) with tectonic tremor and sVLFE activity occurred in Kumano-nada, starting in December 2020 and continuing until the middle of January 2021. In this study, we investigate the spatio-temporal distribution of the sVLFE activity during this SSE using DONET broadband seismometer data. We discuss the variations in the regional characteristics of the sVLFE activity based on their relationship with past activity and structural heterogeneities, which are thought to be related to the seismogenic status, such as the pore pressure along the plate interface and the topographic heterogeneities of the subducted slab at the shallow (up-dip side of the) transition zone.

\section{Methods}

We determined the CMT of the sVLFEs using the method of Nakano et al. (2008) (the SWIFT system), which performs a waveform inversion in the frequency domain to determine the source location, faultorientation parameters, and moment magnitude of the earthquakes. We assumed a pure double-couple source mechanism. Fitting synthetic waveforms to the observed waveforms for each frequency component, we obtained the best-fitting fault-orientation parameters and the location of the source centroid. Both the synthetic waveforms and the source-time functions were obtained via an inverse 
Fourier transform of the estimated parameters in the frequency domain. The moment magnitude was obtained by fitting steplike functions to the obtained source-time function in the frequency range used for the analysis. We determined CMTs of the sVLFEs from the waveforms obtained from broadband seismometers (CMG-3TEBB) at each DONET station.

The setting for the analyses is the same as that of Nakano et al. (2018). We detected the signals by visually inspecting band-pass-filtered waveforms from the continuous records. The waveforms when the sVLFE signals were detected were band-pass-filtered between 0.03 and $0.05 \mathrm{~Hz}$ and then decimated to a sampling interval of $2 \mathrm{~s}$. We used a total data length of $256 \mathrm{~s}$ (128 data points in each channel) for the inversion. Due to the relatively larger noise level of the horizontal components compared with the vertical components, we set the weight of the horizontal components to one-tenth of that of the vertical components in most cases.

The synthetic waveforms were calculated assuming the one-dimensional velocity model representing the study area (Nakano et al. 2013). The best-fitting source location was obtained via a grid search with a horizontal spacing of $0.01^{\circ}$ in latitude and longitude and a vertical (depth) spacing of $1 \mathrm{~km}$. We first determined the source centroid location using velocity seismograms and then estimated the moment tensor at that location using displacement seismograms. Supplementary Figure 1 presents an example of a CMT inversion and displacement waveform fitting for a Mw 3.1 event on December 20, 2020.

We conducted CMT inversions for 681 events that were observed at three or more stations and contained at least one vertical component. Then, we selected the events for discussion using the following criteria: (1) an estimated Mw larger than 3, (2) residuals for the waveform fitting of less than $0.3,(3)$ residuals for the source-time function of less than 0.1 , and (4) at least five waveforms being included in the inversion. We employed the bootstrap method (Efron and Tibshirani 1994) to estimate the standard errors of the source locations and the focal mechanisms for the selected 290 events. Using 500 bootstrap replications, in which the waveform traces were resampled at random and duplications were not discarded, we estimated the errors of the CMT inversion.

\section{Results}

As a result, we obtained 290 CMT solutions of the sVLFEs. The focal depths of most of the sVLFE are between 5 and $8 \mathrm{~km}$, which is close to the depth of the plate boundary in this area (Nakanishi et al. 2018). The average source location errors were $0.03^{\circ}$ in both latitude and longitude (horizontal direction) and 1.3 $\mathrm{km}$ in depth (vertical direction). The average errors of the plunge of the $\mathrm{P}-, \mathrm{T}-$, and $\mathrm{B}$-axes were $34^{\circ}, 32^{\circ}$, and $16^{\circ}$, respectively.

To identify the fault plane where the sVLFEs occur, we examined the CMT solutions. Based on the many structural studies along the Nankai Trough subduction zone (e.g., Nakanishi et al. 2018) and the maximum horizontal direction from the borehole breakout analysis (Lin et al. 2016), we assumed that the strike, dip, and rake angles for typical thrust earthquakes along the plate interface in this study area are $240^{\circ}, 6^{\circ}$, and $90^{\circ}$, respectively, in Kumano-nada. We computed the Kagan angles (Kagan 1991) between 
the sVLFE CMT solutions and a typical interplate thrust. The Kagan angle evaluates the difference between two CMT solutions with an angle between $0^{\circ}$ and $120^{\circ}$. This angle was smaller than $30^{\circ}$ for most of the sVLFEs (Figure 1b). Therefore, most of the sVLFEs that occurred during this episode are likely low-angle thrust-type events consistent with the plate boundary. In addition, we compared the average focal depth and its standard deviation obtained via the bootstrap method with the depth of the plate boundary model (Nakanishi et al. 2018) (Figure 1c). There is a tendency for sVLFEs with smaller Kagan angles to be located at positions $1 \mathrm{~km}$ shallower than the plate boundary. Because the plate boundary model of Nakanishi et al. (2018) shows the depth of the top of the oceanic crust, layer 2, their depth model in this study is relatively deeper than the top of the subducted sediment and the actual plate interface, which corresponds to the plate boundary fault. Therefore, we conclude that most of the detected sVLFEs occur along the plate interface.

sVLFE activity was also observed in 2009, 2015, and 2016 in the active area of this episode (Figure 2a). The sVLFE distribution during this episode can be divided into two major parts: the eastern (E) and western (W) areas in Figures 1 and 2b, respectively. The E area is located south of the KMB stations, whereas the $\mathrm{W}$ area is located between the KMC and KMD stations. Counting the number of sVLFEs that occurred within $0.03^{\circ}$ of the grid points that are spaced $0.01^{\circ}$ horizontally, which corresponds to the average source location errors in horizontal direction and the spacing of the grid search, respectively, the most active region is east of the $E$ area, south of KMB06 (Figure 2b). This location corresponds to the 2015 activity. The cumulative moment of the sVLFEs in the $E$ and $W$ areas shows no significant difference, even though there is a maximum near KMD13 on the western side (Figure 2c). Thus, the moment release per event is larger in the $\mathrm{W}$ area than in the $\mathrm{E}$ area (Figure $2 \mathrm{~d}$ ).

Next, we plotted the sVLFE source locations in the along-trough and along-dip directions (Figure 3a). In this study, time is given as Japanese Standard Time (UTC +9). We find that the activity can be divided into several stages with different migration patterns. The spatial distribution of the relative number of sVLFEs for each stage is presented in Figure 4. The characteristics of the activity for each period are summarized as follows.

Stage 1: December 6-10, 2020

The first sVLFE in this episode occurred at 21:12 JST on December 6,2021 , in the E area. For the next 5 days, the activity was confined in an area with a radius of approximately $5 \mathrm{~km}$ in both the along-dip and along-trough directions around the starting point (Figures $3 \mathrm{a}$ and $4 \mathrm{a}$ ). This area corresponds to the area of sVLFE activity observed in October 2015 (Figure 2a; Nakano et al. 2018; Toh et al. 2020).

Stage 2: December 11-12, 2020

The activity area expanded southwestward parallel to the trough axis, and relatively active sVLFEs were observed south of KMB07 (Figures 3a and 4b). sVLFEs were not detected in this area; however, some activity was observed in March 2009 and April 2016 (Figure 2a; Sugioka et al. 2012; Nakano et al. 2018; Toh et al. 2020). The activity area did not expand in the along-dip direction (Figure 3b). 
sVLFE activity was observed for the first time in the $\mathrm{W}$ area (Figure $4 \mathrm{c}$ and $\mathrm{g}$ ) during this stage, and the active area extended southward, with continuing activity in the area of Stage 2, located south of KMB07 (Figure 4b). This area is part of the sVLFE active areas in March 2009 and April 2016 (Figure 2a; Sugioka et al. 2012; Nakano et al. 2018; Toh et al. 2020). We can confirm that this southward extension of the active area included extensions in both the along-dip and along-trough directions (Figure $3 a$ and $b$ ).

Stage 4: December 15-27, 2020

The active area further extended to the southwest, in the along-trough direction, filling the entire $\mathrm{W}$ area (Figure 3a). However, the number of sVLFEs west of $136.7^{\circ} \mathrm{E}$ was much smaller compared with the activity in 2016 (Figure 2a; Nakano et al. 2018). In the along-dip direction, the active area expanded toward the outer ridge (Figure $4 \mathrm{~d}$ ). In the $\mathrm{E}$ area, the activity was not constant in time; swarm-like activity migrating to the northeast occurred on December 18 and 21. The activity south of KMB07 became inactive in areas where intensive activity had occurred in Stages 2 and 3 (Figure 4d).

Stage 5: December 28-31, 2020

A pronounced northeastward migration was observed across the $\mathrm{W}$ and $\mathrm{E}$ areas (Figure 3a). The activity during this stage occurred in an area that had already been activated in the previous stages, and there was no extension of the active area (Figure 4e).

Stage 6: January 1-17, 2021

During this stage, no sVLFEs were observed in the $E$ area (Figure $4 f$ and $g$ ). The overall activity was low; however, a swarm was observed on January 12 (Figure 3a) in the W area. Even though the total number of sVLFEs was small, the active area appears to have extended close to the trough axis (Figure 4f). Because no sufficiently large sVLFEs were observed to determine the focal mechanism after January 18 , 2021, we defined the end of this stage as January 17, 2021. However, there were many sVLFE-like waveforms that were only observed at KMC21, especially from the middle to the end of January 2021.

\section{Discussion}

\subsection{Location of the sVLFE clusters}

The $W$ area is located offshore between the outer ridge and the outer wedge regions (Figure $2 b$ ). Based on tectonic surveys, this region has a thick shear zone resulting from the accumulation of underthrust sediment near the plate boundary (e.g., Tsuji et al. 2014). Full-wave inversions of the active seismic data (Kamei et al. 2013) and receiver function analyses (Akuhara et al. 2020) suggest that this thick shear zone is rich in fluid. Based on these previous studies, we considered that the existence of pore fluids could have promoted sVLFE activity in the W area during this episode. Shiraishi et al. (2020) proposed that the distribution of sVLFE activity is controlled by the subduction of small-scale ridges. The most 
active part of the W area corresponds to the area where an SVLFE cluster was observed during the 2016 episode; these events were located on the down-dip side of a subducted ridge. This indicates that the dominant sVLFE region might be controlled by structural heterogeneities, such as the geometry of the plate interface, and that structural heterogeneities cause micro-scale heterogeneities of the pore fluid distribution.

The outer wedge up-dip of the E area has a thin shear zone according to the MCS reflection survey (Figure 8 of Hendriyana and Tsuji 2021). Hendriyana and Tsuji (2021) analyzed in detail tremors that occurred in 2015 and 2016 and proposed that the difference in the thickness of the share zone controls the tremor activity; tremors did not directly occur below the outer wedge in the $\mathrm{E}$ area, which has a thin shear zone. Toh et al. (2020) hypothesized that the absence of sVLFE activity up-dip of the E area is due to the presence of the paleo-Zenith Ridge, which suppresses fluid flow from down-dip, and that this ridge forms a fracture network on the upper plate. Our results do not contradict either hypothesis. In addition, if the existence of the subducted paleo-Zenith Ridge suppresses the fluid flow from down-dip, as proposed by Toh et al. (2020), the plate interface beneath the outer ridge area should accumulate fluid. In this case, the fluid from down-dip does not reach the outer wedge area. This heterogeneous distribution of fluids might be related to the active sVLFEs at the outer ridge, as well as the inactivity at the outer wedge in the $E$ area.

\subsection{Migration of sVLFE activities}

Slow earthquakes, including sVLFEs, often show migration, and most researchers believe that this is due to the diffusion of pore fluid or stress (e.g., Ide 2010; Kato and Nakagawa 2020); however, constant velocity migration sometimes occurs (e.g., Yamashita et al. 2015). The diffusion coefficient $D$ is used to express the rate of the spatial evolution as, where $t$ denotes the time. The April 2016 sVLFE activity can be well fitted with $D=3 \times 10^{3} \mathrm{~m}^{2} \mathrm{~s}^{-1}$ (the blue dotted line in Figure 3a) or $4 \mathrm{~km} \mathrm{day}^{-1}$ in both the alongtrough and along-dip directions (Nakano et al. 2018).

In the activity during Stage 1 , in the $E$ area, studied here, $D=1.5 \times 10^{2} \mathrm{~m}^{2} \mathrm{~s}^{-1}$ (the black line in Figure 3a) or $1.5 \mathrm{~km}$ day $^{-1} \mathrm{fits}$ the expansion front of the activity area well in both the trough-parallel and troughorthogonal directions (Figure $3 a$ and b). During Stages 2-4 of the activity in the W area, the spatiotemporal distribution of the sVLFEs projected in the along-trough direction can be fitted with $D=1.5 \times 10^{3}$ $\mathrm{m}^{2} \mathrm{~s}^{-1}$ (the red line in Figure 3a) via diffusion. If we assume a linear velocity for the migration front, 15 $\mathrm{km}$ day $^{-1}$ for Stage 2 and $3 \mathrm{~km}$ day $^{-1}$ for Stages 3 and 4 are obtained. The migration in the along-dip direction is not as clear. As can be seen, the rate of area expansion is larger in the $\mathrm{W}$ area than in the $\mathrm{E}$ area.

The migration velocity may be related to the pore pressure and the energy released during the activity. Kano et al. (2018) carefully investigated deep tremor activities and demonstrated that, at locations where the migration velocity is small, the released energy per event is small, the pore fluid pressure is high, and the number of tremors is large, and vice versa. The E area had a slower migration velocity (Figure $3 a$ and b), lower released energy per event, and larger number of sVLFE occurrences compared with the W area 
(Figure $2 b$ and $d$ ). Even though we do not have sufficient information on the values of the fluid pressure, the fluid pressure may be higher in the $E$ area than in the $\mathrm{W}$ area if we assume that the relationship obtained by Kano et al. (2018) applies here.

If the relationships between the number of events, moment release per event, and migration velocity observed in this study always hold at the same locations, the conditions for sVLFE occurrence, such as the fluid pressure and stress state, are defined by the location. However, the rate of area expansion is different from past activities even in the same activity area. For example, in the $\mathrm{W}$ area, the diffusion coefficient was slightly smaller than that observed in April 2016. The 2016 sVLFE activity was triggered by the April 1, 2016, off-Mie earthquake $(\mathrm{Mw}=6.5)$ on the down-dip side of the western active area (Nakano et al. 2018), whereas the episode investigated here occurred spontaneously. This difference might reflect a temporal change in the stress level or the coupling status around the plate boundary in the source area. Another possibility is that these activities migrated in opposite directions; the 2016 activity started at the western edge of the activity area (distance $=-25 \mathrm{~km}$ in the along-trough direction plot of Figure $3 a$ ). In this case, the migration velocity might also depend on the migration direction. Even though we cannot currently identify why the migration velocities are different, these observations provide a constraint on mechanical models of sVLFE occurrence.

Migrations with much higher velocities than the activity front toward the northeast, opposite to the direction of the activity area expansion, occurred in Stage 5. This is similar to the rapid tremor reversal (RTR; Houston et al. 2011) observed in tectonic tremor activity. We refer to this migration as RTR in this study because of their similarities. The migration is well fitted with a constant velocity of approximately $25 \mathrm{~km}$ day $^{-1}$ or a diffusion coefficient of $D=10^{4} \mathrm{~m}^{2} \mathrm{~s}^{-1}$ (the pink line in Figure 3a). Other RTR-like swarm activities occurred in the E area during Stage 4 and in the W area during Stage 6, with locations close to the ending and beginning points, respectively, of the RTR in Stage 5 (Figure 3b) with very similar migration speeds. Therefore, we assume that these swarms share the nature of the main RTR, and we refer to them as sub-RTR activity (Figure 3). By taking a closer look at the main RTR activity using the source locations obtained in this study with Kagan angles of less than $30^{\circ}$, it can be observed that the migration consists of two groups on lines approximately $10 \mathrm{~km}$ apart (Figure $3 \mathrm{~b}$ ) and that their activities occurred simultaneously. These features suggest that the main RTR occurred with some width in the direction orthogonal to the direction of propagation. The occurrence of these RTR-like activities may indicate a temporal change in the propagation efficiency of the fluid pressure and/or the stress level during this episode or the existence of pore-pressure waves in the plate interface (Cruz-Atienza et al. 2018).

The main RTR and sub-RTR-3 were also reported in a land-based analysis (Takemura et al. 2021), in which the migration velocity was twice as large as that in this study. This difference could be explained by the difference in the location accuracy between the two catalogs. When we compare our sVLFE catalog with that of Takemura et al. (2021) and consider common events as those with a difference in occurrence time within $10 \mathrm{~s}, 75$ events can be matched. In general, the sVLFE distribution of these events based on the catalog of Takemura et al. is wider than that in our result, and the average horizontal 
differences are $0.06^{\circ}$ and $0.07^{\circ}$ in longitude and latitude, respectively. From this comparison, we conclude that the difference in the migration speeds estimated here and by Takemura et al. (2021) is the result of the different accuracies of the locations in the two catalogs.

\subsection{Possible sVLFE activities close to the trough axis}

The sVLFEs for which a CMT solution was accurately obtained in this study are primarily distributed in the area surrounded by stations of Nodes B, C, and D (Figure 2). Activity south of the KMC stations close to the trough axis was rare. Only during Stage 6 were a few sVLFEs observed. In addition, the activity in this region was not detected during the past episodes in November 2015 or April 2016 (Nakano et al. 2018). Beneath the Node $C$ stations, the low-velocity zone in the accretionary prism is thinner than that beneath the KMB and KMD stations (Tonegawa et al. 2017). Tonegawa et al. suggested that sVLFEs are activated in sporadically distributed low-velocity and mechanically weak volumes within the accretionary prism where fluids significantly reduce the shear strength of the faults. In that case, the sVLFE activity should be higher between the KMB and KMD stations than near the KMC stations, which is consistent with the sVLFE distribution during this episode and that in 2016 (Figure 2a and b).

However, we observed low-frequency signals that were very similar to sVLFEs (Figure 5a) at station $\mathrm{KMC21}$, which is closest to the trough axis (Figure 2a). Visual detections of similar signals during the sVLFE episode demonstrated that their activity peaked in the middle of January 2021, during Stage 6 just after sub-RTR-3 (Figure 3), and continued until February 2, 2021 (Figure 5b). One of these events corresponds to an ordinary earthquake detected by the Japan Meteorological Agency; however, others do not. As these signals were not detected at other stations in most cases, we could not estimate their locations or focal mechanisms. However, these observations imply the occurrences of small-scale sVLFEs close to the trough axis. Because the up-dip side of the sVLFE activity area is important for tsunami source predictions, this activity needs to be carefully monitored. From the correspondence between the SSE and sVLFEs (Nakano et al. 2016), the investigation of the up-dip end of the sVLFE activity is also important to determine how shallow of a depth the background SSE reached.

\section{Conclusion}

Based on broadband seismic waveforms obtained from seafloor observations, we determined the CMT solutions of sVLFEs that occurred in the Nankai Trough between December 2020 and January 2021. The main results are as follows:

(1) The activity area of this episode was divided into two parts: the E and W areas. The activity started from the E area, where sVLFE activity was observed in 2015, and then expanded to the southwestern area, where sVLFE activity was observed in 2016.

(2) The characteristics of the activity between the two major active areas are different: the $E$ area is primarily under the outer ridge, whereas the $\mathrm{W}$ area is primarily under the area between the outer ridge and the outer wedge. The observed sVLFE activity pattern corresponds to the location of the subducted of the 
paleo-Zenith Ridge beneath the E area and the difference in the thickness of the shared zone in the outer wedge.

(3) There are also differences in the number of sVLFEs, the magnitude of individual events, and the expansion migration velocity between the $\mathrm{E}$ and $\mathrm{W}$ active areas, which may reflect the differences in the fluid pressures in each region.

(4) Several RTR-like sVLFE migrations were observed. The largest occurred across both the E and W areas, with a 10-km width in the direction perpendicular to the direction of propagation.

(5) At one station near the trough axis, we observed a waveform that suggested a sVLFE. Because the waveform is rarely observed at other stations and the activity was concentrated in mid-January, it is possible that a small-scale sVLFE occurred near the trough axis in the latter half of the episode.

\section{Abbreviations}

sVLFE: shallow very-low-frequency earthquake

SSE: slow-slip event

CMT: centroid moment tensor

OBS: ocean bottom seismometer

DONET: Dense Oceanfloor Network System for Earthquakes and Tsunamis

RTR: rapid tremor reversal

\section{Declarations}

\section{Ethics approval and consent to participate}

Not applicable

\section{Consent for publication}

Not applicable

\section{Availability of data and materials}

DONET waveform data are available at https://doi.org/10.17598/NIED.0008. The program package "SWIFT" is available from M. Nakano upon reasonable request.

\section{Competing interests}


The authors declare no conflicts of interest associated with this manuscript.

\section{Funding}

Not applicable

\section{Authors' contributions}

Yojiro Yamamoto: Formal analysis, investigation, methodology, and writing of original draft.

Keisuke Ariyoshi: Formal analysis, investigation, review, and editing.

Shuichiro Yada: Data curation, investigation, and resources.

Masaru Nakano: Formal analysis, methodology, software, review, and editing.

Takane Hori: Conceptualization, review, and editing.

\section{Acknowledgments}

We appreciate the efforts of the people responsible for the development and maintenance of DONET. We also thank Drs. E. Araki, T. linuma, and S. Takemura for valuable discussion. All figures were drawn using Generic Mapping Tools (GMT) (Wessel and Smith 1991).

\section{References}

1. Akuhara T, Tsuji T, Tonegawa T (2020) Overpressured underthrust sediment in the Nankai Trough forearc inferred from transdimensional inversion of high-frequency teleseismic waveforms. Geophys Res Lett 47. doi:10.1029/2020GL088280

2. Ando $M$ (1975) Source mechanisms and tectonic significance of historical earthquakes along the Nankai Trough, Japan. Tectonophysics 27:119-140. doi:10.1016/0040-1951(75)90102-X

3. Araki E, linuma T, Yamamoto Y, Kimura T, Machida Y, Agata R, Ariyoshi K, Ichimura T, Hori T, Kodaira $S$ (2021) Observation of shallow slow slip event propagating updip to the trough in the Nankai Trough. presented in Japan Geoscience Union Meeting 2021:SCG39-11

4. Araki E, Saffer DM, Kopf AJ, Wallace LM, Kimura T, Machida Y, Ide S, Davis E, IODP Expedition 365 shipboard scientists (2017) Recurring and triggered slow-slip events near the trench at the Nankai Trough subduction megathrust. Science 356:1157-1160. doi:10.1126/science.aan3120

5. Araki E, Yokobiki T, Kawaguchi K, Kaneda Y (2013) Background seismic noise level in DONET seafloor cabled observation network 2013 IEEE International Underwater Technology Symposium (UT):1-4. doi:10.1109/UT.2013.6519858

6. Argus DF, Gordon RG, DeMets C (2011) Geologically current motion of 56 plates relative to the no-netrotation reference frame. Geochem Geophys Geosyst 12:n/a-n/a. doi:10.1029/2011GC003751 
7. Ariyoshi K, linuma T, Nakano M, Kimura T, Araki E, Machida Y, Sueki K, Yada S, Nishiyama T, Suzuki K, Hori T, Takahashi N, Kodaira S (2021) Characteristics of slow slip event in March 2020 revealed From borehole and DONET observatories. Front Earth Sci 8. doi:10.3389/feart.2020.600793

8. Behr WM, Bürgmann R (2021) What's down there? The structures, materials and environment of deep-seated slow slip and tremor. Philos Trans A Math Phys Eng Sci 379:20200218. doi:10.1098/rsta.2020.0218

9. Bird P (2003) An updated digital model of plate boundaries. Geochem Geophys Geosyst 4:1027. doi:10.1029/2001GC000252

10. Cruz-Atienza VM, Villafuerte C, Bhat HS (2018) Rapid tremor migration and pore-pressure waves in subduction zones. Nat Commun 9:2900. doi:10.1038/s41467-018-05150-3

11. Efron B, Tibshirani RJ (1994) An Introduction to the Bootstrap. (1st ed.). Chapman and Hall/CRC, New York. doi:10.1201/9780429246593

12. Hendriyana A, Tsuji T (2021) Influence of structure and pore pressure of plate interface on tectonic tremor in the Nankai subduction zone, Japan. Earth Planet Sci Lett 558. doi:10.1016/j.epsl.2021.116742

13. Houston H, Delbridge BG, Wech AG, Creager KC (2011) Rapid tremor reversals in Cascadia generated by a weakened plate interface. Nat Geosci 4:404-409. doi:10.1038/ngeo1157

14. Ide S (2010) Striations, duration, migration and tidal response in deep tremor. Nature 466:356-359. doi:10.1038/nature09251

15. Kagan YY (1991) 3-D rotation of double-couple earthquake sources. Geophys J Int 106:709-716. doi:10.1111/j.1365-246X.1991.tb06343.x

16. Kamei R, Pratt RG, Tsuji T (2013) On acoustic waveform tomography of wide-angle OBS datastrategies for pre-conditioning and inversion. Geophys J Int 194:1250-1280. doi:10.1093/gji/ggt165

17. Kaneda Y, Kawaguchi K, Araki E, Matsumoto H, Nakamura T, Kamiya S, Ariyoshi K, Hori T, Baba T, Takahashi N (2015) Development and application of an advanced ocean floor network system for megathrust earthquakes and tsunamis. In: Seafloor Observatories. Springer, Heidelberg, Germany, pp. 643-666

18. Kano M, Kato A, Ando R, Obara K (2018) Strength of tremor patches along deep transition zone of a megathrust. Sci Rep 8:3655. doi:10.1038/s41598-018-22048-8

19. Kato A, Nakagawa S (2020) Detection of deep low-frequency earthquakes in the Nankai subduction zone over 11 years using a matched filter technique. Earth Planets Space 72. doi:10.1186/s40623020-01257-4

20. Kawaguchi K, Kaneko S, Nishida T, Komine T (2015) Construction of the DONET real-time seafloor observatory for earthquakes and tsunami monitoring. In: Seafloor Observatories. Springer, Heidelberg, Germany, pp. 211-228

21. Lin W, Byrne TB, Kinoshita M, McNeill LC, Chang C, Lewis JC, Yamamoto Y, Saffer DM, Casey Moore J, Wu H-Y, Tsuji T, Yamada Y, Conin M, Saito S, Ito T, Tobin HJ, Kimura G, Kanagawa K, Ashi J, Underwood MB, Kanamatsu T (2016) Distribution of stress state in the Nankai subduction zone, 
southwest Japan and a comparison with Japan Trench. Tectonophysics 692:120-130.

doi:10.1016/j.tecto.2015.05.008

22. Nakanishi A, Takahashi N, Yamamoto Y, Takahashi T, Ozgur Citak S, Nakamura T, Obana K, Kodaira S, Kaneda Y (2018) Three-dimensional plate geometry and P-wave velocity models of the subduction zone in SW Japan: implications for seismogenesis. In: Geol Tectonics Subduction Zones Tribi Gaku Kimura. doi:10.1130/2018.2534(04)

23. Nakano M, Hori T, Araki E, Kodaira S, Ide S (2018) Shallow very-low-frequency earthquakes accompany slow slip events in the Nankai subduction zone. Nat Commun 9:984. doi:10.1038/s41467-018-03431-5

24. Nakano M, Hori T, Araki E, Takahashi N, Kodaira S (2016) Ocean floor networks capture lowfrequency earthquake event. Eos 97. doi:10.1029/2016E0052877

25. Nakano M, Kumagai H, Inoue H (2008) Waveform inversion in the frequency domain for the simultaneous determination of earthquake source mechanism and moment function. Geophys $\mathrm{J}$ Int 173:1000-1011. doi:10.1111/j.1365-246X.2008.03783.x

26. Nakano M, Nakamura T, Kamiya S, Kaneda Y (2014) Seismic activity beneath the Nankai Trough revealed by DONET ocean-bottom observations. Mar Geophys Res 35:271-284. doi:10.1007/s11001-013-9195-3

27. Nishimura T, Yokota Y, Tadokoro K, Ochi T (2018) Strain partitioning and interplate coupling along the northern margin of the Philippine Sea plate, estimated from Global Navigation Satellite System and Global Positioning System-Acoustic data. Geosphere 14:535-551. doi:10.1130/GES01529.1

28. Obana K, Kodaira S (2009) Low-frequency tremors associated with reverse faults in a shallow accretionary prism. Earth Planet Sci Lett 287:168-174. doi:10.1016/j.epsl.2009.08.005

29. Obara K, Kato A (2016) Connecting slow earthquakes to huge earthquakes. Science 353:253-257. doi:10.1126/science.aaf1512

30. Park J-O, Moore GF, Tsuru T, Kodaira S, Kaneda Y (2004) A subducted oceanic ridge influencing the Nankai megathrust earthquake rupture. Earth Planet Sci Lett 217:77-84. doi:10.1016/S0012$821 \times(03) 00553-3$

31. Shelly DR, Beroza GC, Ide S, Nakamula S (2006) Low-frequency earthquakes in Shikoku, Japan, and their relationship to episodic tremor and slip. Nature 442:188-191. doi:10.1038/nature04931

32. Shiraishi K, Yamada Y, Nakano M, Kinoshita M, Kimura G (2020) Three-dimensional topographic relief of the oceanic crust may control the occurrence of shallow very-low-frequency earthquakes in the Nankai Trough off Kumano. Earth Planets Space 72. doi:10.1186/s40623-020-01204-3

33. Sugioka H, Okamoto T, Nakamura T, Ishihara Y, Ito A, Obana K, Kinoshita M, Nakahigashi K, Shinohara M, Fukao Y (2012) Tsunamigenic potential of the shallow subduction plate boundary inferred from slow seismic slip. Nat Geosci 5:414-418. doi:10.1038/NGE01466

34. Takemura S, Matsuzawa T, Noda A, Tonegawa T, Asano Y, Kimura T, Shiomi K (2019a) Structural characteristics of the Nankai Trough shallow plate boundary inferred from shallow very low frequency earthquakes. Geophys Res Lett 46:4192-4201. doi:10.1029/2019GL082448 
35. Takemura S, Noda A, Kubota T, Asano Y, Matsuzawa T, Shiomi K (2019b) Migrations and clusters of shallow very low frequency earthquakes in the regions surrounding shear stress accumulation peaks along the Nankai Trough. Geophys Res Lett 46:11830-11840,840. doi:10.1029/2019GL084666

36. Takemura S, Obara K, Shiomi K, Baba S (2021) Spatiotemporal Variations of Shallow Very Low Frequency Earthquake Activity Southeast off the Kii Peninsula, along the Nankai Trough, Japan. Earth and Space Science Open Archive, 23. https://doi.org/doi:10.1002/essoar.10507824.1

37. Tamaribuchi K, Kobayashi A, Nishimiya T, Hirose F, Annoura S (2019) Characteristics of shallow lowfrequency earthquakes off the Kii Peninsula, Japan, in 2004 revealed by ocean bottom seismometers. Geophys Res Lett 46:13737- 13745. doi:10.1029/2019GL085158

38. Toh A, Chen WJ, Takeuchi N, Dreger DS, Chi WC, Ide S (2020) Influence of a subducted oceanic ridge on the distribution of shallow VLFEs in the Nankai Trough as revealed by moment tensor inversion and cluster analysis. Geophys Res Lett 47. doi:10.1029/2020GL087244

39. Tonegawa T, Araki E, Kimura T, Nakamura T, Nakano M, Suzuki K (2017) Sporadic low-velocity volumes spatially correlate with shallow very low frequency earthquake clusters. Nat Commun 8:2048. doi:10.1038/s41467-017-02276-8

40. Tsuji T, Kamei R, Pratt RG (2014) Pore pressure distribution of a mega-splay fault system in the Nankai Trough subduction zone: insight into up-dip extent of the seismogenic zone. Earth Planet Sci Lett 396:165-178. doi:10.1016/j.epsl.2014.04.011

41. Wessel P, Smith WHF (1991) Free Software Helps Map and Display Data. Eos Trans. AGU 72:441.

42. Yamashita Y, Yakiwara H, Asano Y, Shimizu H, Uchida K, Hirano S, Umakoshi K, Miyamachi H, Nakamoto M, Fukui M, Kamizono M, Kanehara H, Yamada T, Shinohara M, Obara K (2015) Geophysics. Migrating tremor off southern Kyushu as evidence for slow slip of a shallow subduction interface. Science 348:676-679. doi:10.1126/science.aaa4242

43. Yokota Y, Ishikawa T (2020) Shallow slow slip events along the Nankai Trough detected by GNSS-A. Sci Adv 6:eaay5786. doi:10.1126/sciadv.aay5786

44. Yokota $Y$, Ishikawa T, Watanabe S, Tashiro T, Asada A (2016) Seafloor geodetic constraints on interplate coupling of the Nankai Trough megathrust zone. Nature 534:374-377. doi:10.1038/nature17632

\section{Figures}




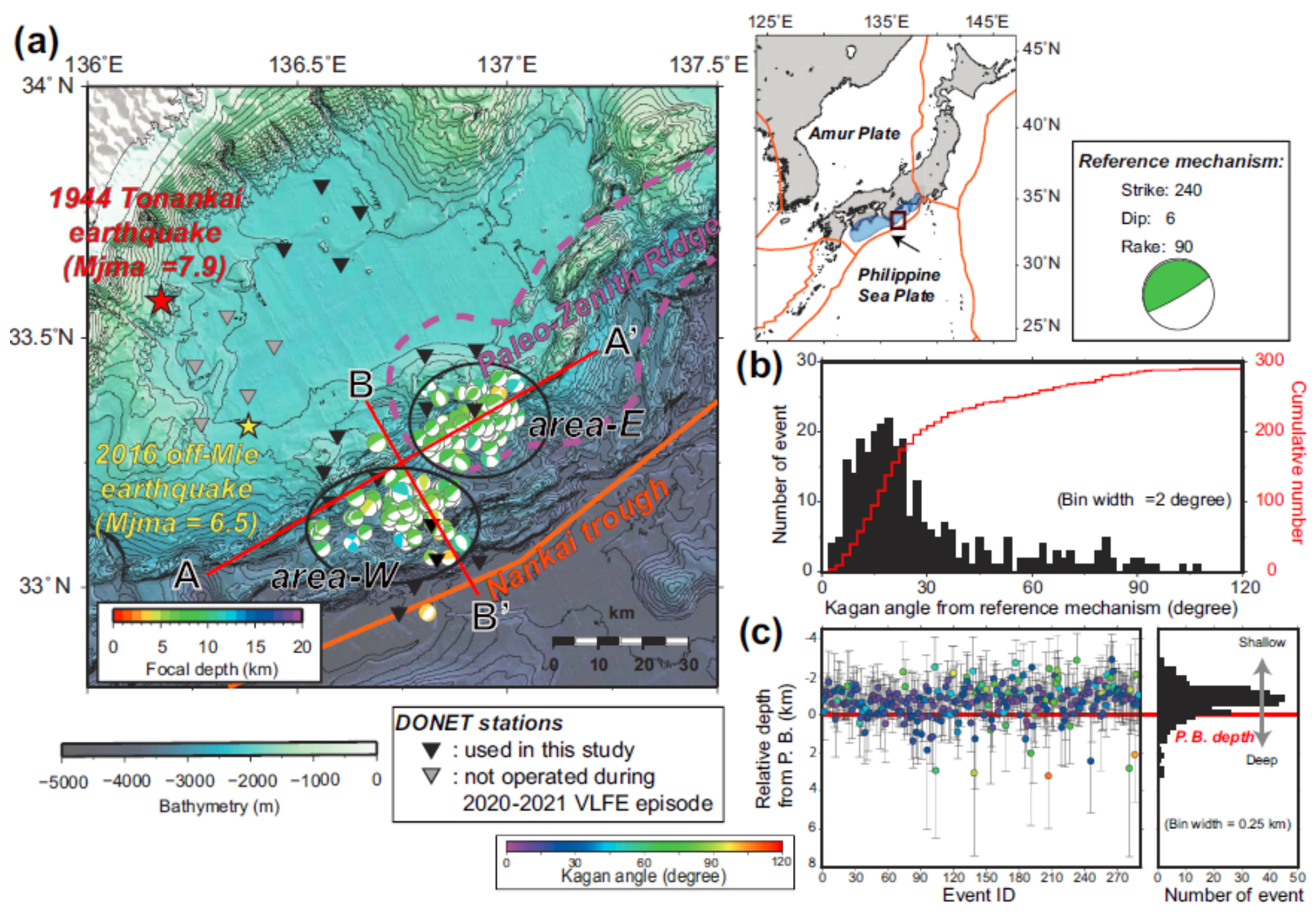

\section{Figure 1}

Study area and observed shallow very-low-frequency earthquake (sVLFE) distribution. (a) Distribution of the centroid moment tensor (CMT) solutions of the sVLFEs and the Dense Oceanfloor Network System for Earthquakes and Tsunamis (DONET) stations on a bathymetry map. The color of the CMT solutions indicates the focal depth. The area outlined by the pink dashed line indicates the location where the paleo-Zenith Ridge subducted (Park et al. 2004). The epicenters of the 1944 Tonankai and 2016 off-Mie earthquakes are indicated by red and yellow stars, respectively. The right-top panel shows the regional map and the surrounding plate boundaries (Bird 2003). The dark brown rectangle indicates the area shown in panel (a). Blue-masked areas correspond to the assumed areas of the Tokai, Tonankai, and Nankai seismogenic zones. The arrow shows the relative motion vector of the Philippine Sea Plate to the Amur Plate (Argus et al. 2011). (b) Distribution of the Kagan angle of the CMT solutions with respect to the reference mechanism assuming a pure thrust fault along the plate boundary. (c) Relationship between the average focal depth estimated using the bootstrap method and the plate boundary model (Nakanishi et al. 2018). The color and the vertical bar in the left panel indicate the Kagan angle with the reference mechanism and the standard deviation of the depth estimation, respectively. 
(a)
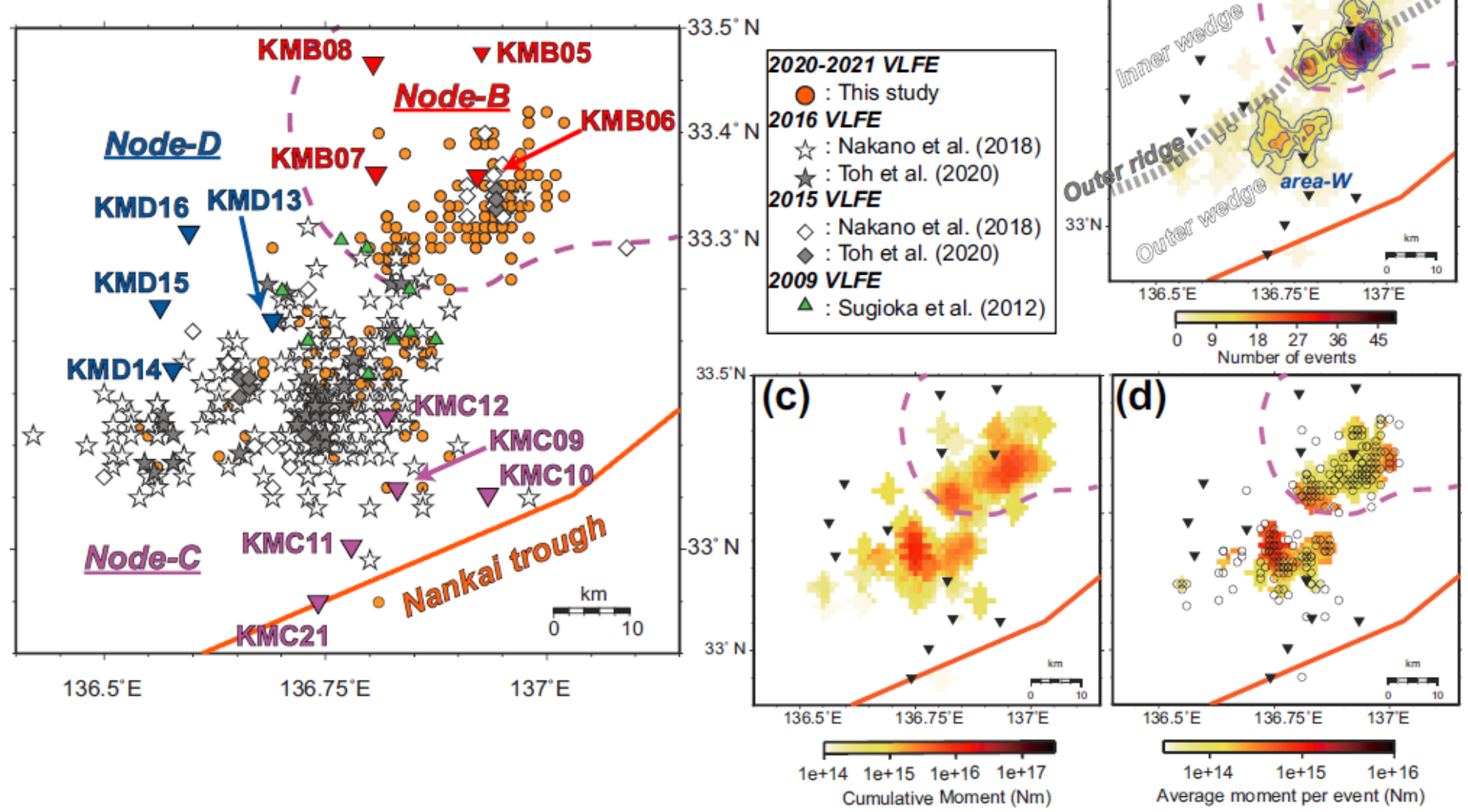

Figure 2

Details of the sVLFE distribution. (a) Spatial distribution of the sVLFEs obtained in this and the previous studies. The DONET node and station codes are also shown. (b) Heatmap of the sVLFE activity for the entire episode. The background color and blue contours indicate the event number within $0.03^{\circ}$ at each point. The contour interval is 5 . The locations of the outer ridge, outer wedge, and inner wedge based on the bathymetry map are also shown. (c) Distribution of the cumulative moment release amount at each point. (d) Distribution of the moment release amount per event at each point. The open circles indicate the sVLFEs detected in this study. 


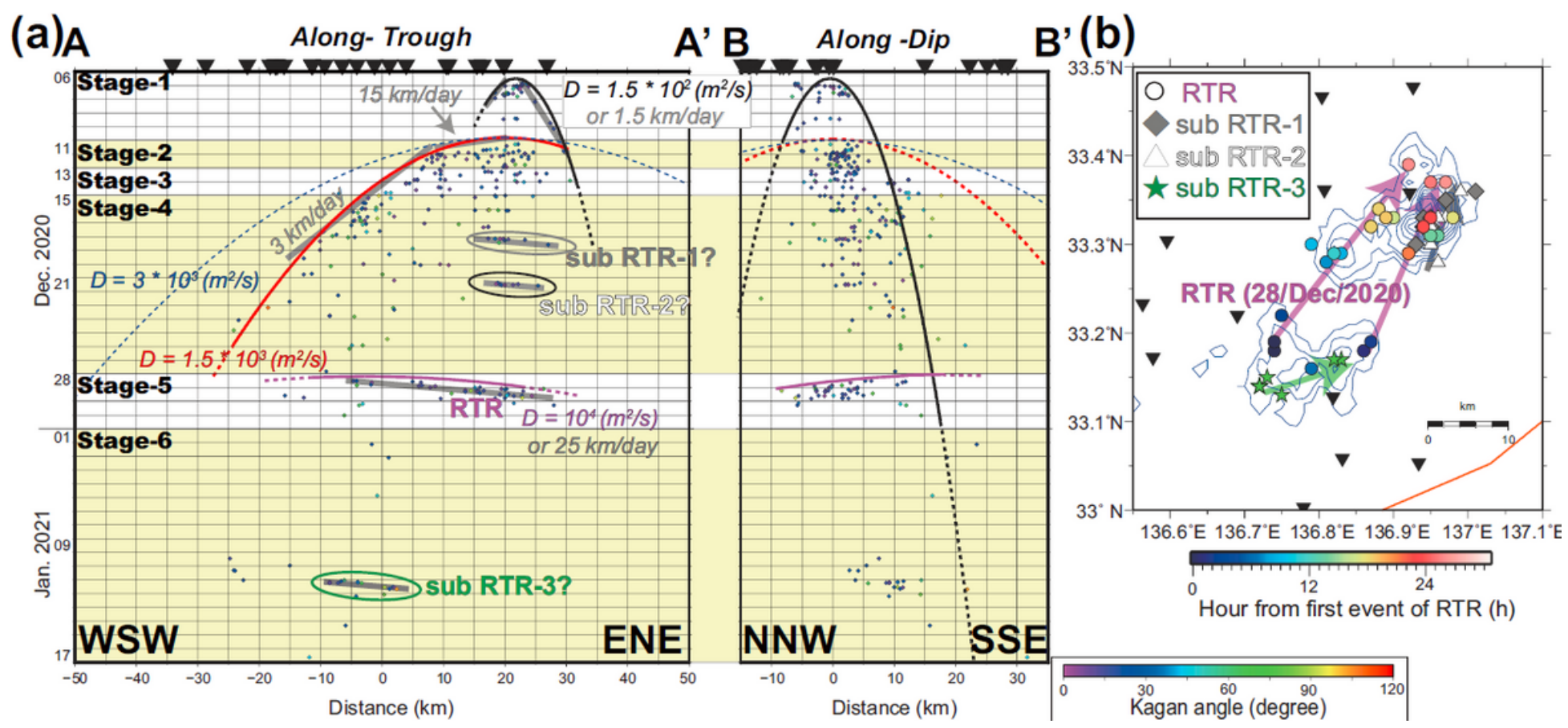

Figure 3

Spatio-temporal distribution of the sVLFEs in this episode. (a) Along-trough and along-dip directions. The definition of these directions is presented in Figure 1a. The white and yellow background colors indicate the periods of each stage. The circles indicate the projected locations of the sVLFEs with the color indicating the Kagan angle with respect to the reference focal mechanism shown in Figure 1b. (b) Map view of the spatial distribution for rapid tremor reversal (RTR) and sub-RTR-1, sub-RTR-2, and sub-RTR-3. Only sVLFEs with Kagan angles with respect to the reference focal mechanism of less than $30^{\circ}$ are plotted. The color of the circles indicates the elapsed time from the first RTR event. Pink, gray, and green vectors indicate the approximate migration direction for RTR, sub-RTR-3, and sub-RTR-1 and sub-RTR-2, respectively. Other symbols are the same as in Figure $2 \mathrm{~b}$. 

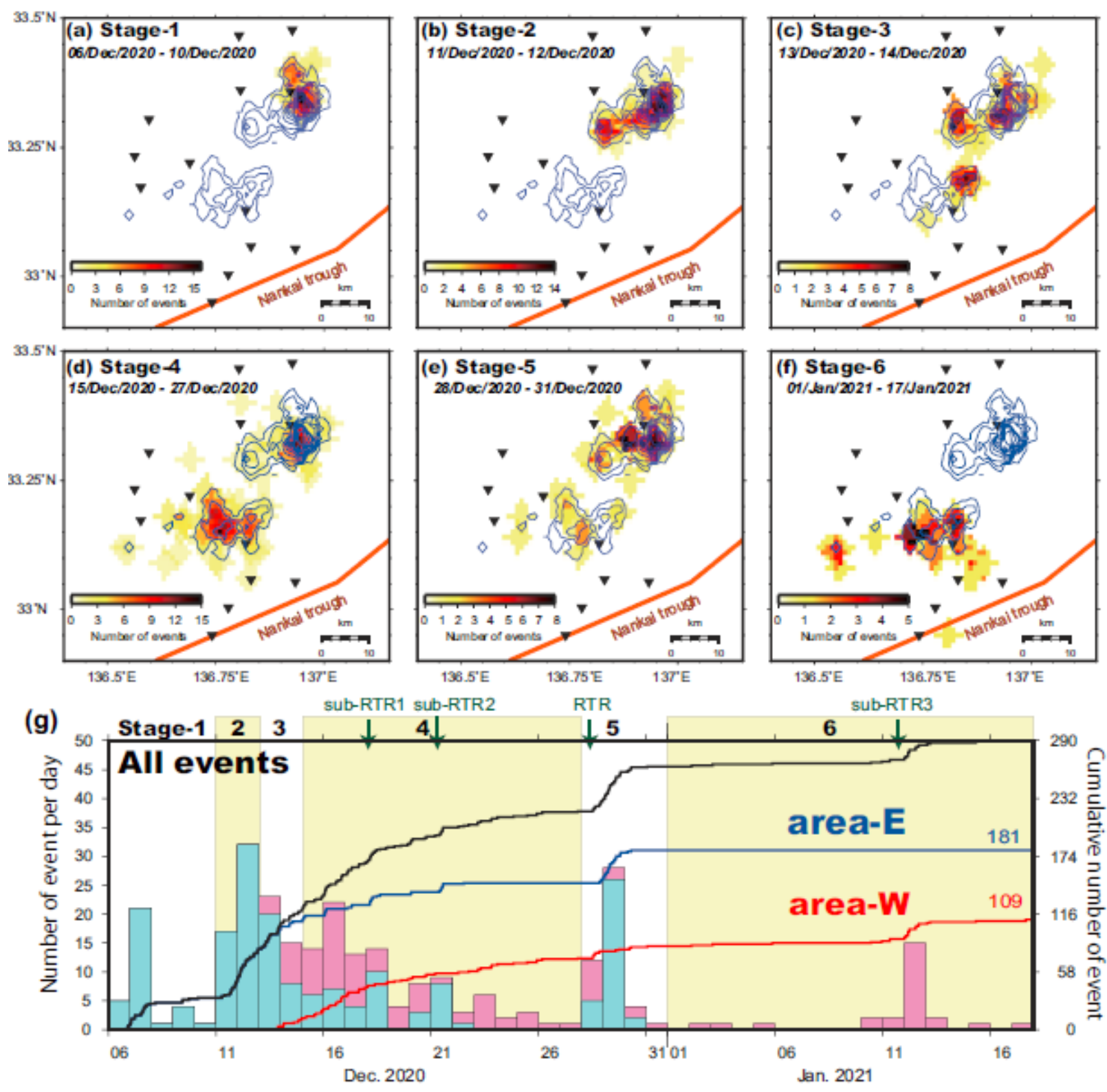

\section{Figure 4}

Heatmap during this sVLFE episode for (a) Stage 1, (b) Stage 2, (c) Stage 3, (d) Stage 4, (e) Stage 5, and (f) Stage 6. Other symbols are the same as in Figure 2b. (g) Histogram of the sVLFEs. The height of the bars indicates the number of earthquakes per day, and the colors within the bars indicate the breakdown of the number of sVLFEs by area: eastern (E; sky-blue) and western (W; pink). The black, blue, and red lines are the cumulative number of sVLFEs in all catalogs, the $\mathrm{E}$ area, and the $\mathrm{W}$ area, respectively. 


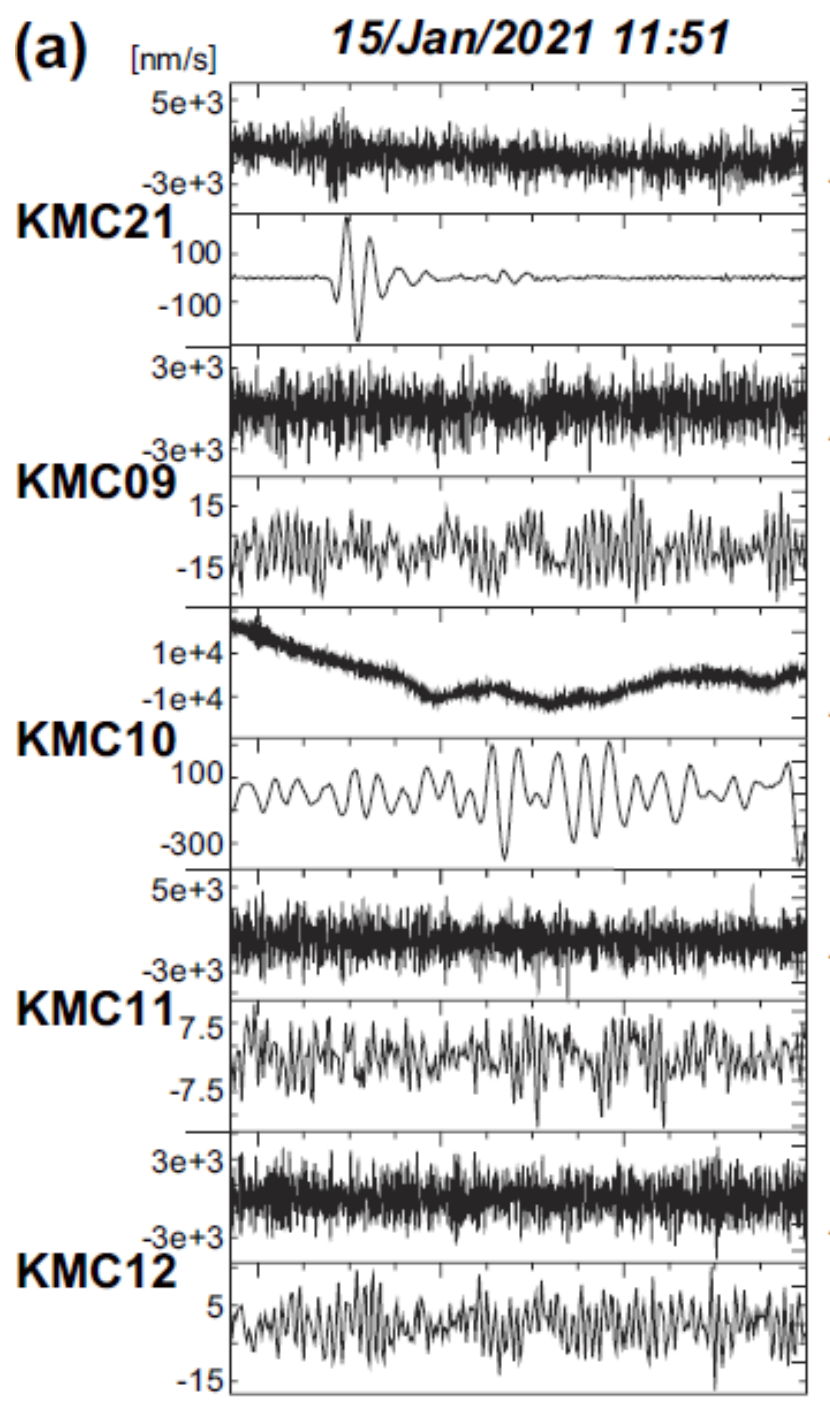

17/Jan/2021 15:44

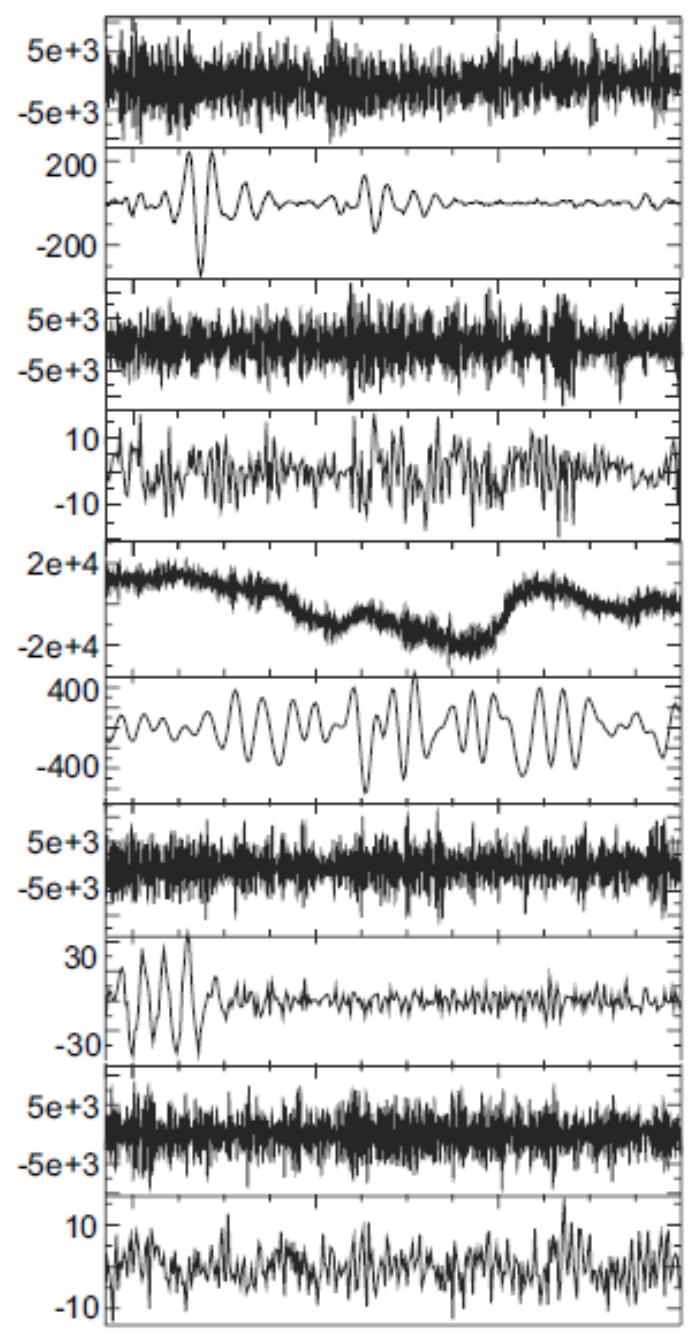

(b)

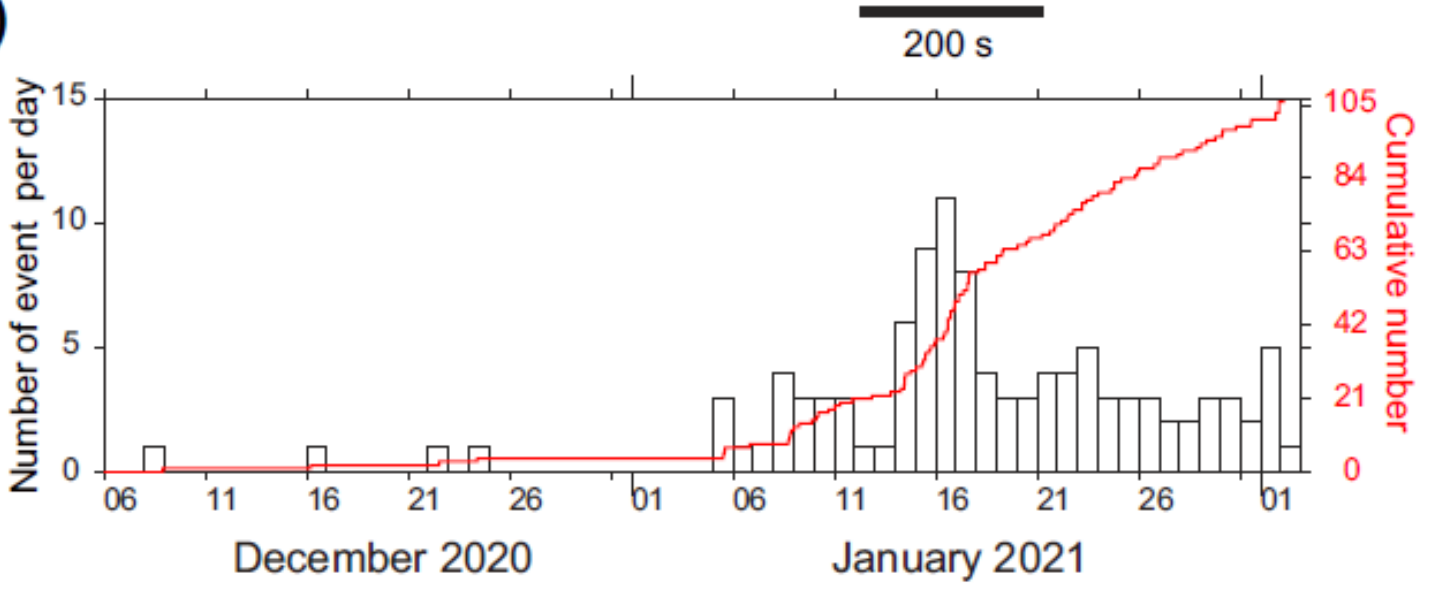

Figure 5

sVLFE-like activity close to the trough axis. (a) Examples of the observed waveform at Node C. For each station, the upper panel shows the original velocity waveform reduced to the trend, and the lower panel shows the band-pass-filtered velocity waveforms (see details in text). Note that the waveform at the $\mathrm{KMC10}$ station has larger noise than those at other stations as this station is not buried beneath the seafloor. (b) Histogram of the sVLFE-like waveforms observed at KMC21. 


\section{Supplementary Files}

This is a list of supplementary files associated with this preprint. Click to download.

- FigS1.eps

- Graphicabstract211104.png 